\title{
Biochemical and Biological Study on The Effect of Flaxseed on Rats Suffer from Nephropathy.
}

\author{
Hanaa. H. El-Sayed ${ }^{*}$, Abd El-Moneim. H. Darwish ${ }^{*}$, Ensaf. M.Ysein ${ }^{* *}$. Ghada. \\ D. zehairy ${ }^{* *}$. \\ *Nutritional Biochemistry and Metabolism Dept., National Nutrition Institute Cairo, Egypt. \\ ${ }^{* *}$ Nutrition and Food Science Dept., Faculty of Home Economics, Al-Azhar University.
}

\begin{abstract}
The present study was conducted to investigate the effect supplemented diets with different doses of flaxseed on some biological, biochemical and histopathology changes in rats suffering from nephropathy. Thirty adult male albino rats "Sprague Dawley strain" weighing (170-175g) were divided into two main groups, the first main group fed on basal diet as a (negative control group). The second main group (24 rats) injection with $10 \mathrm{ml}$ glycerol $\mathrm{kg}$ dissolve in saline solution (glycerol / saline solution $\mathrm{v} / \mathrm{v}$ ) to induce renal failure, the dose of glycerol were injected under slight diethyl ether anesthesia. The second main group divided into four subgroups, the first subgroup fed standard diet (positive control group). The second subgroup fed standard diet containing 3\% flaxseed. The third subgroup fed standard diet containing 5\% flaxseed. The forth subgroup fed standard diet containing $7 \%$ flaxseed. At the end of the experiment (4 weeks), blood samples were taken; serum was separated and subjected to biochemical analysis (renal function). Glutathione, Malondialdehyde and histopathology were exanimated in kidney tissue in all groups. The results indicated that all treated groups get better in body weight gain\%, Kidney functions (urea, uric acid and creatinine in serum) and GSH and MDA renal tissue ameliorated especially in renal failure rats fed on diet containing $5 \%$ and $7 \%$ flaxseed.
\end{abstract}

Key words: nephropathy, flaxseed, rats.

\section{Introduction}

Robert et al., (2004) mentioned that Acute renal failure (ARF) is characterized by sudden loss of the kidneys to excrete wastes, concentrate urine, conserve electrolytes, and maintain fluid balance, is a frequent clinical problem, particularly in the intensive care unit, where it is associated with a mortality of between $50 \%$ and $80 \%$.

Renal failure is characterized by abrupt and sustained decline in glomerular filtration rate, which leads to accumulation of urea and other chemicals in the blood (Kellum et al., 2011).

Definition and diagnosis of acute kidney injury are based on changes in creatinine, which is an inadequate marker and might identify patients when it is too late. The incidence of acute kidney injury is rising and increases with advancing age (Anderson et al., 2011).

Acute kidney injury (AKI), causes are numerous and include low blood volume from any cause, exposure to substances harmful to the kidney, and obstruction of the urinary tract (Webb and Dobb, 2007).

The overall mortality rate of RF is about $45 \%$; however, the mortality rate of sepsis-induced RF is about 70\%. In addition, sepsis is the most common trigger of RF (Mori et al., 2010).

Flaxseed (Linum usitatissimum) is one such alternative, and it has gained popularity as a dietary supplement. Flaxseed is the richest known source of lignans, one of the three major classes of phytoestrogens, and is also a rich source of $\alpha$-linolenic acid (ALA) and soluble and insoluble fibers. Despite the increasing popularity of flaxseed as a dietary supplement, no large randomized clinical trials of its effects (Dodin et al., 2005).

Lignans are one of the major classes of phytoestrogens, which are estrogen-like chemicals and also act as antioxidants (Milder et al., 2005).

Haliga et al., (2009) showed that Dietary flaxseed supplementation in diabetes mellitus may have beneficial effects on diabetic nephropathy evolution by reducing the levels of oxidative stress and increasing the antioxidant defense systems.

\section{Material And Method:}

Materials:

1. Chemicals: casein" $85 \%$ protein", corn starch, DL-methionine, choline chloride, vitamins, minerals, glycerol required was obtained from El-Gomhorya Company for chemicals and Drugs, Cairo, Egypt.

2. Flaxseed and sunflower oil required for preparing experimental diets were purchased from local market, Cairo, Egypt. 
3. Experimental animals: Thirty healthy adult male albino rats "Sprague Dawley strain" weighing (170175g.) were obtained from vaccine and immunity organization Helwan Farm, Cairo, Egypt.

4. Kits were obtained from El-Gomhorya Company for chemicals and drugs, Cairo, Egypt.

\section{1-Biological Experiment: - induction of renal failure:}

\section{Methods:}

Nephropathy was induced in normal healthy rats by injection of $(10 \mathrm{mg} / \mathrm{kg})$ "body weight". Saline solution/ glycerol (v/v) after fasting overnight under slight anesthesia. Control rats received sham injections into hind limbs under the same amount of anesthesia according to the method were described by (Nobuhito et al., 1999).

C) Diets:

Standard diet was prepared from fine ingredients per 100g. The diet had the following composition: sunflower oil 10\%; salt mixture $4 \%$ according to Hegested et al, (1941), vitamin mixture $1 \%$ according to Reeves et al., (1993) choline chloride $0.2 \%$, DL-methionine $0.3 \%$ and protein was added.

Experimental diet was prepared from standard diet with $12 \%$ protein according to AIN, (1993) adding with flaxseed at $3,5,7 \mathrm{~g} / 100 \mathrm{gm}$ diet.

\section{D) Experimental design}

Thirty healthy adult male albino rats "Sprague Dawley strain" weighing (170-175g.) four weeks old were divided into five groups of six rats each with similar total body weight and were housed individually in wire cages.

* The first main group (6 rats) fed on basal diet as a negative control group.

* The second main group: (24 rats) were induced with glycerol 50\% (v/v) glycerol in $0.9 \%$ saline solution at $10 \mathrm{ml} / \mathrm{kg} \mathrm{B} . W$. to induce renal failure in rats (Shibata et al., 1999).

The second main group was divided into four subgroups as a following:

* The first subgroup (6rats) was acute renal failure fed standard diet (as a positive control group).

* The second subgroup (6rats) fed standard diet containing $3 \mathrm{~g} / 100 \mathrm{~g}$ diet of flaxseed.

* The third subgroup (6rats) fed standard diet containing $5 \mathrm{~g} / 100 \mathrm{~g}$ diet of flaxseed.

* The forth subgroup (6rats) fed standard diet containing $7 \mathrm{~g} / 100 \mathrm{~g}$ diet of flaxseed.

Food and water were prepared ad-libitum during the period of experiment (4 wk.); food was calculated and weight of animals was recorded twice weekly.

At the end of experiment, the animals were fasted overnight, and then sacrificed under anesthesia. Blood samples were taken in dry centrifuge tubs from hepatic portal vein. Serum was separated at 3000 round per minute (rpm) for 10 minutes and kept in plastic vial at $-20^{\circ} \mathrm{c}$ until analysis. Kidney was removed, cleaned in saline solution, and dried by filter paper and weighed.

\section{E) Chemical analysis}

Uric acid (UA), blood nitrogen urea (BNU) and serum creatinine (Cr) were determined. Malondialdehyde (MDA) and glutathione (GSH) evaluated in kidney tissue homogenate.

\section{2- Biological parameters:-}

During the experimental (4 weeks), the consumed diet was recorded every day (feed intake), and body weight was recorded every week. Biological evaluation of the different diets was carried out by determination of body weight gain \% (BWG \%) feed efficiency ratio (FER) according to chapman et al., (1959), using the following equations.

BWG\% = Final weight $(\mathrm{g})$-initial weight $(\mathrm{g}) /$ Initial weight $(\mathrm{g}) \times 100$

Feed efficiency= Body weight $/$ Food intake

\section{Result And Discussion:}

Table (1) indicates effect of supplemented different doses from flaxseed (FS) on feed intake (FI) per gram and body weight gain \% (BWG \%) of rats suffering from renal failure.

As shown in this table, it could be noticed that mean value of FI "g/day" of rats suffering from renal failure (control "+" group) was markedly significant decrease $\mathrm{p}<0.05$ than that of the healthy normal rats (control "-" group). Table (1) and figures $(1,2)$ indicates effect of supplemented different doses from flaxseed (FS) on feed intake (FI) per gram, body weight gain \% (BWG \%) and feed efficiency ratio (FER) of rats suffering from acute renal failure. 
Also, the control $(+)$ group revealed a high significantly decreased $\mathrm{p}<0.05$ in mean value of FER compared with those of the control (-) group.

With regard to table (1), it could be observed that the mean of FER for acute renal failure rats fed on diet containing 3\%, 5\% and 7\% FS, were significantly decreased, compared with that the control (-). On the other hand, these values were significantly increased, as compared to the control (+) group.

With regard to table (1), it could be observed that the mean of FER for acute renal failure rats fed on diet containing $7 \%$ FS, were significantly increased, compared with that the acute renal failure rats fed on diet containing $3 \%$ and $5 \% \mathrm{FS}$.

The decrease of FI in renal failure may be due to accumulation of urea and nitrogen containing substances in the blood stream which lead to a number of symptoms, such as fatigue, loss of appetite, nausea and vomiting as stated by (Skorecki et al., 2005).

Regarding to table (1), it could be observed that treat groups feeding rate on 3\%, 5\%,7\% FS led to a significant increase $\mathrm{p}<0.05$ in the mean values of FI in comparison to those of the control $(+)$. On the other hand, those values were significantly decreased, as compared to the control (-) group. These variations may be due to the palatability and odor of oil in flaxseed.

Also, the control (+) group revealed a high significantly decreased $\mathrm{p}<0.05$ in mean value of BWG compared with those of the control (-) group. This observation is due to infected rats with nephropathy which is catabolic more than anabolic. It could be accounted by the body's inability to utilize glucose. So, it tries to overcome this by lipolysis and muscle degradation for obtaining energy. Consequently, the weight losses occur, as implied by (Lameire et al., 2005) who mentioned that hyperglycemia adversely affects the prognosis for patients with AKI.

It could be noticed that the mean value of BWG $\%$ of nephropathy rats fed on 3\%, 5\% and $7 \%$ from flaxseed were significantly increased in comparison to that of the untreated acute renal failure rats (control "+" group). On the other hand, these values were significantly decreased, as compared to the control (-) group. This observation may be due to the degradation of body tissues.

Ferreira Medeiros de França Cardozo et al., (2011) supported the present findings when they studied the effects of chronic intake of flaxseed upon hematologic parameters and immunological findings on body development of Wistar rats. They concluded that supplementation with flaxseed seems to be beneficial to maintenance or reduction of body mass.

Fukumitsu et al., (2008) showed that lignan secoisolariciresinol diglucoside (SDG) to mice significantly reduced high-fat diet-induced visceral and liver fat accumulation, hyperlipaemia, hypercholesterolaemia, hyperinsulinaemia and hyperleptinaemia.

Also, these findings are supported by Park and Velasquez (2012) who reported that the lignanenriched flaxseed powder (LEFP) supplementation may provide beneficial effects such as the reduction of body weight and fat accumulation, the lipid profile improvement, and blood pressure control.

GSH and MDA renal tissue of rats fed standard diet, with glycerol and with different dose from flaxseed are presented in table (2). Untreated nephropathy rats (control "+" group) a highly significant decrease in the mean value of significant decrease $p<0.05$ in the mean value of glutathione (GSH), compared with the healthy normal rats (control "-" group).

This is accordance with Collins et al., (2003) who stated that glycerol-induced deterioration of renal function in rat kidneys involved histopathology changes in renal tubules, GSH depletion.

Singh et al., (2012) stated that enhanced generation of hydrogen peroxide in renal cortex in rats with glycerol-induced renal failure.

It could be observed that diet supplemented with the three doses of flaxseed "3\%, 5\% and 7\%" caused a significant increase $p<0.05$ in the mean value of GSH, compared with the control (+) group. But in the same time, it significant increased this value in 7\% and 5\% FS groups and significantly decreased this value in 3\% FS group, as compared to the control (-) group.

It is noticed the dietary supplementation with flaxseed at levels (5\% and 7\%) induced a significant increase $\mathrm{p}<0.05$ in the mean value of GSH, compared with that of the dietary supplementation with flaxseed at level (3\%). But in the same time, these values showed significant increase $\mathrm{p}<0.05$ in the GSH, as compared to the control (+) group.

It could be noticed that the control (+) group showed a highly significant increase $p<0.05$ in the mean value of lipid peroxidation (MDA), compared with the control (-) group.

Data in table (2) indicated that, diet supplemented with flax at "3\%,5\% and 7\%" caused a significant decrease $\mathrm{p}<0.05$ in the mean values of MDA, in comparison to those of the control (+) group. In the same time, the treatment 3\% FS did not reach up to the control (-) group.

Data in table (2) indicated that diet supplemented with flaxseed at "5\% and 7\%" caused a significant decrease in the mean value of MDA, in comparison to those of the supplemented with flaxseed at "3\%". 
Data in table (2) indicated that, diet supplemented with flax at "5\% and 7\%" caused a highly significant reduction $\mathrm{p}<0.05$ in the mean value of MDA, in comparison to those of the control (+) group. But in the same time, two doses " 5\%, 7\% FS showed no significant difference in mean MDA, as compared to the control (-) group.

These findings is supported by Jin and John, (1995) who mentioned that phytic acid (PA) is a natural antioxidant and is suggested to have potential functions of reducing lipid peroxidation and as a preservative in foods. Finally, certain inositol phosphates, which derived from PA, have been noted to have a function in second messenger transduction systems.

However, the present result disagreed with the results were obtained by Bhatia et al., (2006) who reported that, increased activity of acid phosphatase and oxidized glutathione was significantly inhibited by linseed oil.

This is consistence with Makni et al., (2010) who investigated the hypoglycemic and antioxidant effects of Flax and Pumpkin seeds mixture on the kidney of alloxan-induced diabetic rats. They found that diet supplemented with Flax and Pumpkin seeds mixture ameliorated the antioxidant enzymes activities observed in diabetic rats and significantly decreased MDA levels.

The findings is accordance with both Hemmings and Song, (2004) who reported that flax consumption effects an increase in the activity of liver gamma GT at the level of the plasma membrane which is lignan dependent, physiologically relevant and may be linked to hepatoprotection against injury through an increase in reduced glutathione, and Hemmings et al, (2005) who mentioned that hepato-protection is through a flax lignan-induced increase in reduced glutathione related to a flax effect on the activity of liver gamma GT in the resting state and the maintenance of its activity in response to injury.

Renal functions in serum of rats fed standard diet, with glycerol and with different dose from flaxseed are presented in table (3).

It could be observed that the control $(+)$ group showed a highly significant increase $(p<0.05)$ in the mean values of blood urea nitrogen (BUN), uric acid (UA) and creatinine (Cr), compared with those of the control (-) group.

This observation due to acute renal failure effect which cause a dysfunction of renal system where diagnosis of acute kidney injury (AKI) relies on increased serum creatinine, oliguria or decline in urine output as stated by (Vlahovic et al., 2007 and Sauriyal et al., 2011).

This can be attributed to the increase rates of renal dysfunction as a result of injection with glycerol, as implied by (Nobuhito et al., 1999).

It could be observed that diet supplemented with flaxseed at levels " 3\%, 5\% and 7\%" a significant increase in the mean value of urea nitrogen, uric acid and creatinine, respectively, compared with the control (-) group. In the same time, diet supplemented with "5\% and 7\% from FS" caused a low significant increase in the mean values of the same parameters, compared with the control (-) group.

In present findings revealed that the doses " 3\%, 5\% and 7\% from flaxseed induced improvement in serum urea nitrogen, uric acid and creatinine, compared with the rats untreated group (control "+"group).

Results introduced in table (3) is noticed, using "5\% and 7\%" from flaxseed are more efficient in reducing serum uric acid, urea nitrogen and creatinine than using $3 \%$ FS.

This is in consistence with Abdel Moneim et al, (2011) who stated treatment with flaxseed oil significantly improved the kidney function.

These findings were supported by Salmean et al., (2012) who determined the effect of foods with added fiber on blood urea nitrogen (BUN) and serum creatinine concentrations in patients with chronic kidney disease (CKD). They concluded that increasing fiber intake in CKD patients through the consumption of foods with added fiber may reduce serum creatinine levels and improve estimated glomerular filtration rate (GFR).

Also, these results were supported by Koguchi, et al., (2004) who indicated that, the dietary fiber suppresses the elevation of uric acid and urea concentration in serum by attenuating the absorption of dietary adenine.

Also, Ranich et al., (2001) said that nutritional intervention studies have shown that consumption of soy-based protein and flaxseed reduces proteinuria and attenuates renal functional or structural damage in animals and humans with various forms of chronic renal disease.

These findings is accordance with both (Ogborn et al., 2006) flax oil (FO) reduced proteinuria in both male and female PKD, and (Abdel Moneim et al., 2011) investigated the effects of flaxseed oil $(1000 \mathrm{mg} / \mathrm{kg}) \mathrm{on}$ the outcome of renal cytotoxicity induced by lead acetate $(20 \mathrm{mg} / \mathrm{kg})$ in male rats. They found reduction in uric acid, urea and creatinine, lipid peroxidation, nitric oxide and increased glutathione levels during flaxseed oil treatment. They results suggested that role of flaxseed oil in limiting renal cytotoxicity-induced by lead acetate as a model for lead toxicity. 


\section{Recommendations:}

Using flaxseeds in foods are more effective on inhibiting oxidative stress and this may be act as a protective against chronic diseases such as renal failure, liver, diabetes and hyperlipidemia.

Adding flaxseed to the diets offered to acute renal failure patients, as it showed beneficial effects on most parameters studied.

The lifestyle intervention program, together with intake from flaxseed seemed to produce important beneficial effects on the nutritional management, physical performance, and clinical parameters of acute renal failure patients.

\section{References}

[1] Abdel Moneim , E.A.; Dkhil, A.M. and Al-Quraishy, S. (2011): The protective effect of flaxseed oil on lead acetate-induced renal toxicity in rats. Journal of Hazardous Materials.; 194: 250-255.

[2] AIN American Institute of Nutrition, (1993): Purified Diets for Laboratory Rodents Final Report Ad Committee on the Reformulation of the AIN Rodent Diet. J. of Nutr. 123:1939-1951.

[3] Anderson, S.; Eldadah, B.; Halter, J.B.; Hazzard, W.R.; Himmelfarb, J.; Horne, F.M.; Kimmel, P.L.; Molitoris, B.A.; Murthy, M.; O'Hare, A. M.; Schmader, K. E. and High, K.P. (2011): Acute kidney injury in older adults. J. Am Soc Nephrol., 22(1): 28-38.

[4] Bellomo, R.; Ronco, C.; Kellum, J. A.; Mehta, R. L. and Palevsky, P. (2004): "Acute renal failure - definition, outcome measures, animal models, fluid therapy and information technology needs: the Second International Consensus Conference of the Acute Dialysis Quality Initiative (ADQI) Group". J. Crit Care 8 (4): 204-12.

[5] Bhatia, L.A.; Manda, K.; Patni, S. and Sharma, L.A. (2006): Prophylactic Action of Linseed (Linum usitatissimum) Oil Against Cyclophosphamide-Induced Oxidative Stress in Mouse Brain. J Med Food; 9 (2):000-000.

[6] Chapman, D.G.; Castilla, R. and Campbell, J.A. (1959): Evaluation of protein in food. I. A. Method for the determination of protein efficiency ratio. Can. J. Biochem. Phyysiol. 37: 679-686.

[7] Collins, F.T.; Sprando, L.R.; Black, N.T.; Olejnik, N.; Wiesenfeld, W. P.; Babu, S.U.; Bryant, M.; Flynn, J.T. and Ruggles, I.D. (2003): Effects of flaxseed and defatted flaxseed meal on reproduction and development in rats. Food and Chemical Toxicology.; 41( 6), 819-834.

[8] disease. J. Ren Nutr.;11(4):183-93.

[9] Dodin, S.; Lemay, A.; Jacques, H.; Légaré, F.; Forest, J.C. and Mâsse, B. ( 2005): The effects of flaxseed dietary supplement on lipid profile, bone mineral density, and symptoms in menopausal women: a randomized, double-blind, wheat germ placebocontrolled clinical trial. J. Clin Endocrinol Metab.; 90(3): 1390-1397.

[10] Ferreira Medeiros de França Cardozo, L.; Leal Soares, L.; Cardozo Brant, L.H.; Alves Chagas, M.; Alves Pereira, V.; Coca Velarde, LG. and Teles Boaventura G. (2011): Hematologic and immunological indicators are altered by chronic intake of flaxseed in Wistar rats. Nutr Hosp.;26(5):1091-6.

[11] Fukumitsu, S.; Aida, K.; Ueno, N.; Ozawa, S.; Takahashi, Y. and Kobori, M.(2008): Flaxseed lignan attenuates high-fat dietinduced fat accumulation and induces adiponectin expression in mice. Br J. Nutr.;100(3):669-76.

[12] Haliga, R.; Mocanu, V.; Păduraru, I.; Stoica, B.;Oboroceanu, T. and Luca V. (2009): Effects of dietary flaxseed supplementation on renal oxidative stress in experimental diabetes. Rev Med Chir Soc Med Nat Iasi.;113(4):1200-4.

[13] Hegested, D.M.; Mills, R.C.; Elvehjer, C.A. and Hart, E.B. (1941): Choline in chicks, J. Biol. Chem., 138: $459-466$.

[14] Hemmings, S. J.; Westcott, N.; Muir, A. and Czechowicz, D. (2004): The effects of dietary flaxseed on the Fischer 344 rat: Liver gamma-glutamyl transpeptidase activity. Cell Biochem Funct. ; 22(4):225-31.

[15] Hemmings, S.J. and Song, X. (2005): The effects of dietary flaxseed on the Fischer 344 rat. III. Protection against CCl(4)-induced liver injury. Cell Biochem Funct.; 23(6):389-98.

[16] Jin, R.Z. and John, W.E. (1995): Phytic acid in health and disease. Critical Reviews in Food science and Nutrition. 35 (6): $495-508$.

[17] Kellum, J.A.; Unruh, M.L. and Murugan, R. (2011): Acute kidney injury. Clin Evid, 28; pii: 2001.

[18] Koguchi, T.; Koguchi, T.; Naka Jima, H.; Takano, S. (2004): Dietary fiber suppresses elevation of uric acid and urea nitrogen concentration in serum rats with renal dysfunction induced by dietary adinine. Int. J. Vitam. Nutr. Res. 74(4): $253-263$.

[19] Lameire, N.; Van Biesen, W. and Vanholder, R. (2005): "Acute renal failure". J. Lancet .; 365 (9457): 417-30.

[20] Makni, M.; Sefi, M.; Fetoui, H.; Garoui. El, M.; Gargouri, N. K.; Boudawara, T. and Zeghal, N. (2010): Flax and Pumpkin seeds mixture ameliorates diabetic nephropathy in rats. Food Chem Toxicol, 48(8-9):2407-12.

[21] Milder, I.E.; Arts, I.C.; van, de.; Putte, B.; Venema, D.P. and Hollman, P. C. (2005): "Lignan contents of Dutch plant foods: a database including lariciresinol, pinoresinol, secoisolariciresinol and matairesinol". Br. J. Nutr.; 93 (3): $393-402$.

[22] Mori, T, Shimizu, T. and Tani, T. (2010): Septic acute renal failure. Contrib Nephrol.;166:40-6.

[23] Nobuhito, S.; Takahiro, O.; Nobuo, H.; Tokuzo, M. and Akira, Y. (1999): Influnence of glycerol-induced acute renal failure on the pharmacokinetics of cycloporin in rats. J. Pharm. Pharmacol, 51: 397-404.

[24] Ogborn, M.R.; Nitschmann, E.; Bankovic-Calic, N.; Weiler, H.A. and Aukema, H. M.(2006): Effects of flaxseed derivatives in experimental polycystic kidney disease vary with animal gender. Lipids.; 41(12):1141-9.

[25] Park, J.B. and Velasquez, M.T. (2012): Potential effects of lignan-enriched flaxseed powder on bodyweight, visceral fat, lipid profile, and blood pressure in rats. Fitoterapia.; 83(5):941-6.

[26] Ranich, T, Bhathena, S. J. and Velasquez, M. T. (2001): Protective effects of dietary phytoestrogens in chronic renal

[27] Reeves, P. G.; Nielsen, F. H. and Fahey, G. C. (1993): AIN-93. purified diets for laboratory rodents: Final report of the American Institute of Nutrition. Ad. Hoc writing committee on the reformulation of the AIN-76. A rodent diet, J. Nutr., 123: $1939-1951$.

[28] Robert, W.; Schrier; Wang, W.; Poole, B. and Mitra, A. (2004): Acute renal failure: definitions, diagnosis, pathogenesis, and therapy. J. Clin Invest.;114(1):5-14.

[29] Salmean, Y. A.; Segal, M. S.; Langkamp-Henken, B.; Canales, M. T.; Zello, G. A. and Dahl, W.J. (2012): Foods with Added Fiber Lower Serum Creatinine Levels in Patients with Chronic Kidney Disease. J. Ren Nutr. 20(5):329-33.

[30] Sauriyal, D.S.; Jaggi, A.S.; Singh, N.and Muthuraman, A. (2011): Investigating the role of endogenous opioids and KATP channels in glycerol-induced acute renal failure. FundamClin Pharmacol,(in press). DOI: 10.1111/j.1472-8206.2011.00936.x.

[31] Shibata, N.; Ohmae, T.; Hoshino, N.; Minouchl, T. and Yanaji, A. (1999): Influence of glycerol-induced acute renal failure on the pharmacokinetics of cycosporin in rats. J. pharm. Pharmacol.; 51: 397-404.

[32] Singh, P.A.; Muthuraman, A.; Jaggi, S.A.; Singh, N.; Grover1, K. and Dhawan, R. (2012): Animal models of acute renal failure. Pharmacological Reports, 64: 31.44 . 
[33] Skorecki, K., Green, J. and Brenner, B.M. (2005): "Chronic renal failure". In Kasper DL, Braunwald E, Fauci AS, et al.. Harrison's Principles of Internal Medicine (16th ed.). New York, NY: McGraw-Hill. pp. 1653-63. ISBN 0-071-39140-1.

[34] Vlahović, P.; Cvetković, T.; Savić, V. and Stefanović, V. (2007): Dietary curcumin does not protect kidney in glycerol-induced acute renal failure. Food Chem Toxicol.; 45(9):1777-82.

[35] Webb, S. and Dobb, G. (2007): ARF, ATN or AKI? It's now acute kidney injury. Anaesthesia and Intensive Care, 35 (6): $843-4$.

Table (1): Effect of supplemented diet with flaxseed on food intake and body weight gain\% of rats suffering from acute renal failure (means \pm S.E)

\begin{tabular}{|c|c|c|c|c|}
\hline \multicolumn{2}{|c|}{ Groups } & Food intake g/day/rat & Body weight gain \% & Feed efficiency \\
\hline \multicolumn{2}{|r|}{ Basal diet (control -) } & $11.45^{\mathrm{a}} \pm 0.33$ & $11.92^{f} \pm 0.75$ & $1.459^{\mathrm{a}} \pm 0.27$ \\
\hline \multirow{4}{*}{ 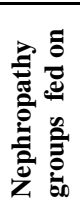 } & Basal diet (control +) & $9.80^{\mathrm{b}} \pm 0.43$ & $2.35^{\mathrm{e}} \pm 1.6$ & $0.502^{\mathrm{e}} \pm 0.34$ \\
\hline & Diet containing $3 \% \mathrm{FS}$ & $10.05^{\mathrm{c}} \pm 0.23$ & $9.16^{\mathrm{c}} \pm 1.03$ & $0.928^{\mathrm{d}} \pm 0.47$ \\
\hline & Diet containing $5 \%$ FS & $10.38^{\mathrm{d}} \pm 0.17$ & $5.82^{\mathrm{a}} \pm 2.1$ & $1.079^{c} \pm 0.36$ \\
\hline & Diet containing $7 \%$ FS & $10.85^{\mathrm{e}} \pm 0.25$ & $3.99^{\mathrm{d}} \pm 2.4$ & $1.155^{\mathrm{b}} \pm 0.35$ \\
\hline \multicolumn{2}{|c|}{ P. value } & 0.0097 & 0.0093 & 0.042 \\
\hline
\end{tabular}

Values are expressed as mean \pm SE. Significant at $\mathrm{p}<0.05$ using one way ANOVA test. Values which have different letters differ significantly, while those with have similar or partially are non-significant.

Table (2) MDA and GSH renal tissue of rats fed standard diet, with glycerol and with different dose from flaxseed (mean \pm S.E).

\begin{tabular}{|c|c|c|c|}
\hline \multirow{2}{*}{\multicolumn{2}{|c|}{ Groups }} & $\begin{array}{l}\text { Glutathione } \\
\text { (GSH) }\end{array}$ & $\begin{array}{l}\text { Lipid peroxidation } \\
\text { (MDA) }\end{array}$ \\
\hline & & $\mathrm{M} \mathrm{mol} / \mathrm{g}$ & $\mathrm{mol} / \mathrm{g}$ \\
\hline \multicolumn{2}{|c|}{ Basal diet (control -) } & $1.283 \mathrm{e} \pm 0.155$ & $6.30 \mathrm{f} \pm 0.228$ \\
\hline \multirow{4}{*}{ 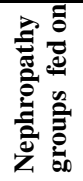 } & Basal diet (control +) & $0.595 \mathrm{~d} \pm 0.080$ & $8.127 \mathrm{a} \pm 0.341$ \\
\hline & Diet containing 3\% FS & $0.979 \mathrm{c} \pm 0.042$ & $7.275 \mathrm{c} \pm 0.283$ \\
\hline & Diet containing 5\% FS & $1.419 \mathrm{f} \pm 0.232$ & $6.759 \mathrm{f} \pm 0.641$ \\
\hline & Diet containing 7\% FS & $1.521 \mathrm{f} \pm 0.278$ & $6.488 \mathrm{f} \pm 0.204$ \\
\hline \multicolumn{2}{|c|}{ P. value } & 0.0038 & 0.01 \\
\hline
\end{tabular}

Values are expressed as mean \pm SE. Significant at $\mathrm{p}<0.05$ using one way ANOVA test.

Values which have different letters differ significantly, while those with have similar or partially are non-significant.

Table (3) renal functions in serum of rats fed standard diet, with glycerol and with different dose from flaxseed (mean \pm S.E)

\begin{tabular}{|c|c|c|c|c|}
\hline \multirow{2}{*}{\multicolumn{2}{|c|}{$\begin{array}{ll}\text { Groups } & \text { parameters } \\
\end{array}$}} & Urea nitrogen & Uric acid & Creatinine \\
\hline & & \multicolumn{3}{|c|}{$\mathrm{mg} / \mathrm{dl}$} \\
\hline \multicolumn{2}{|c|}{ Basal diet (control -) } & $52.4^{\mathrm{a}} \pm 4.6$ & $1.62^{\mathrm{a}} \pm 0.32$ & $0.449^{\mathrm{a}} \pm 0.05$ \\
\hline \multirow{4}{*}{ 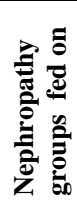 } & Basal diet (control +) & $89.08^{c} \pm 6.8$ & $4.37^{\mathrm{c}} \pm 0.87$ & $0.902^{\mathrm{c}} \pm 0.03$ \\
\hline & Diet containing 3\% FS & $63.65^{\mathrm{d}} \pm 4.4$ & $2.41^{\mathrm{d}} \pm 0.56$ & $0.602^{\mathrm{d}} \pm 0.04$ \\
\hline & Diet containing $5 \%$ FS & $59.21^{\mathrm{e}} \pm 8.56$ & $2.1^{\mathrm{ab}} \pm 0.51$ & $0.56^{\mathrm{ab}} \pm 0.04$ \\
\hline & Diet containing $7 \%$ FS & $55.45^{\mathrm{f}} \pm 3.04$ & $2.13^{\mathrm{ab}} \pm 0.34$ & $0.523^{\mathrm{ab}} \pm 0.09$ \\
\hline \multicolumn{2}{|c|}{ P. value } & 0.00129 & 0.00524 & 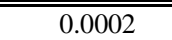 \\
\hline
\end{tabular}

Values are expressed as mean \pm SE. Significant at $p<0.05$ using one way ANOVA test. Values which have different letters differ significantly, while those with have similar or partially are non-significant. 
Normal control (C "-")

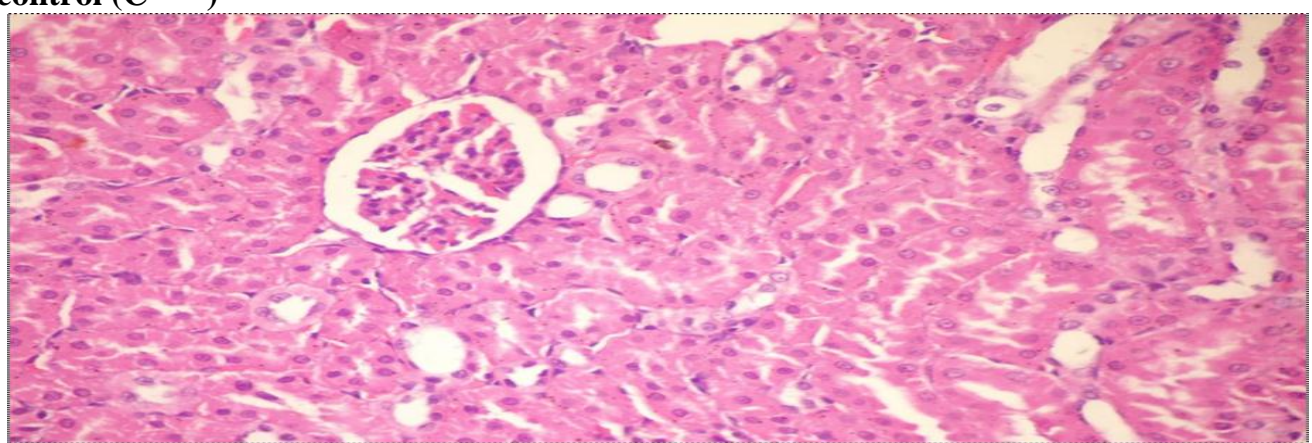

Photo (1): Normal kidney section showing normal orientation of nephrons with adequate glomerui and well-spaced tubules ( $\mathrm{H}$ and $\mathrm{E}, \mathrm{x400})$.

Control positive $\left(\mathrm{C}^{\prime \prime}+"\right)$

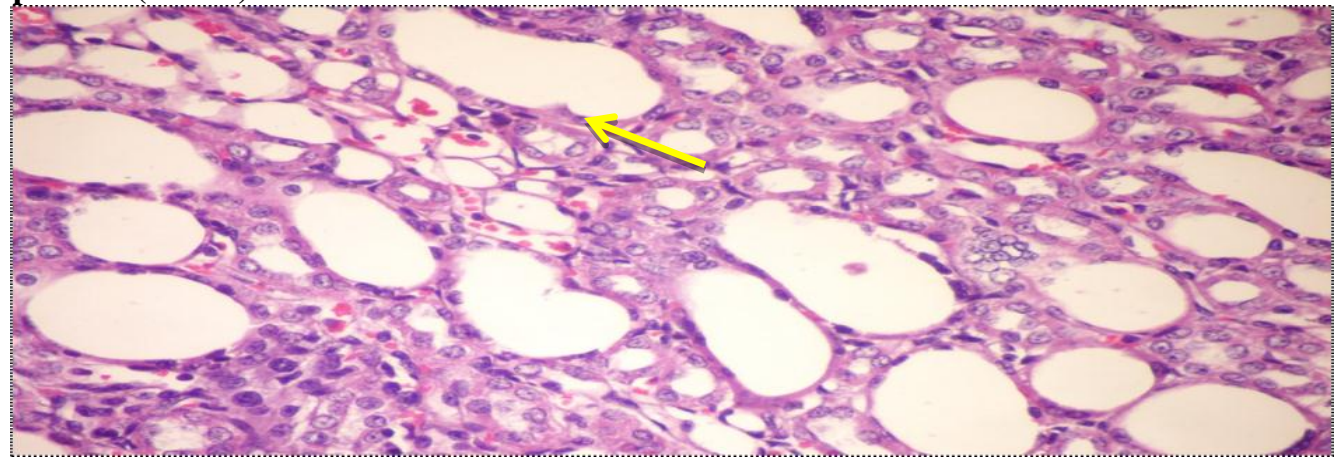

Photo (2): glycerol treated group showing cystic dilation of renal tubules (H and E, x400).

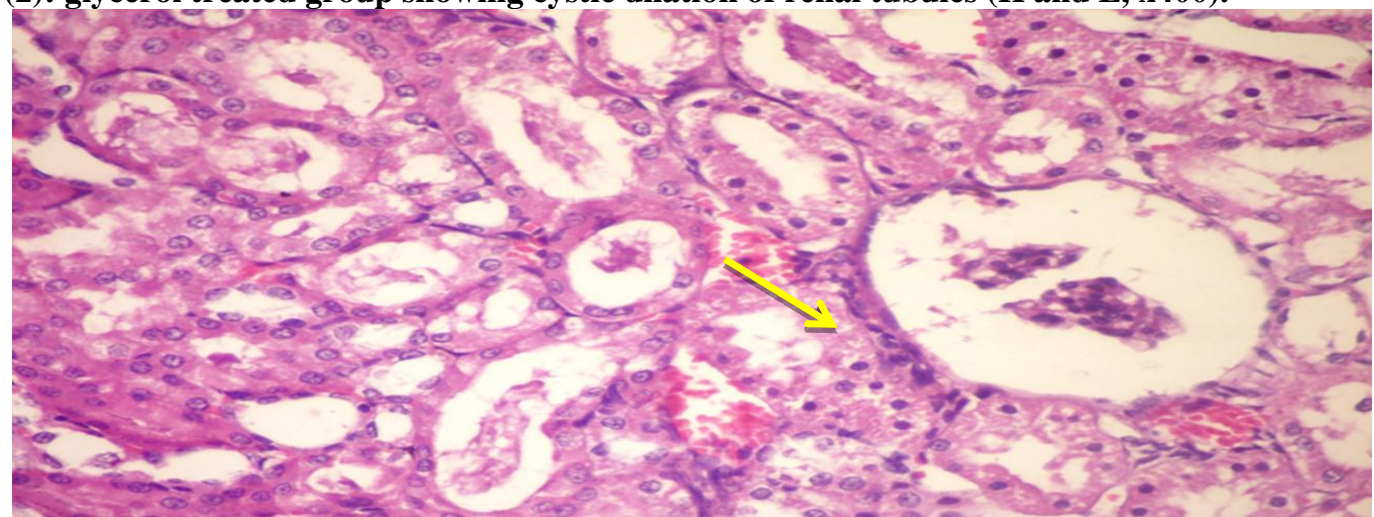

Glycerol treated group showing atrophy of glomerular tufet, distension of Bowman's space and necrobiotic changes of renal tubular epithelium $(\mathrm{H}$ and $\mathrm{E}, \mathrm{x400}$

Case No 3 = treated group with "3\% flaxseed"

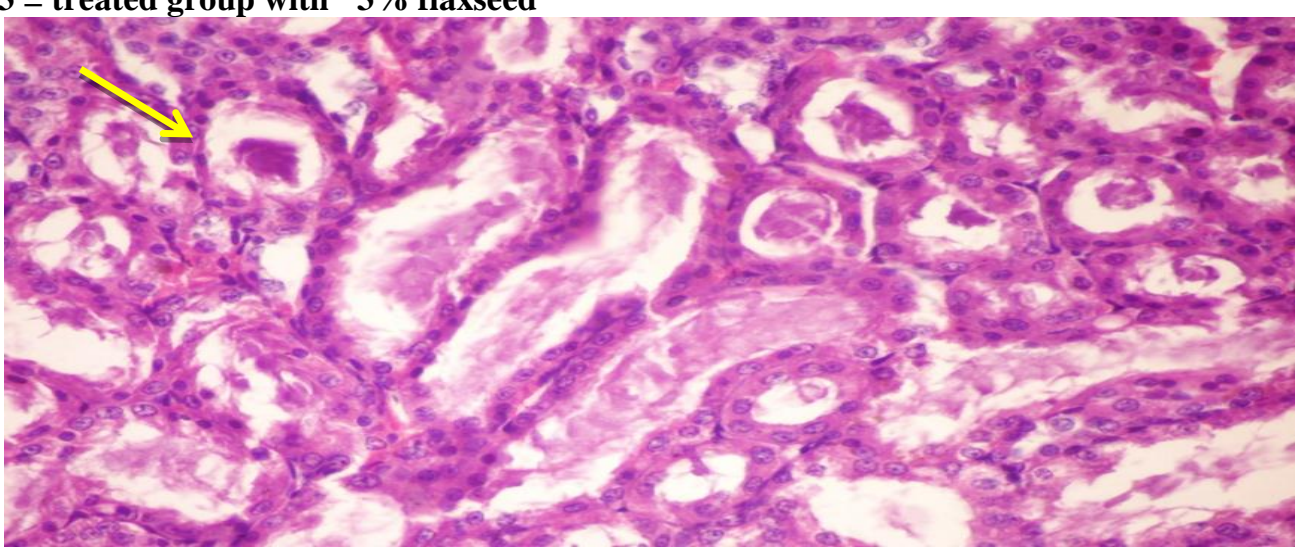


Biochemical and Biological Study on The Effect of Flaxseed on Rats Suffer from Nephropathy.

Treated group with "3\% flaxseed" showing eosinophilic protein cast in the lumen of renal tubules

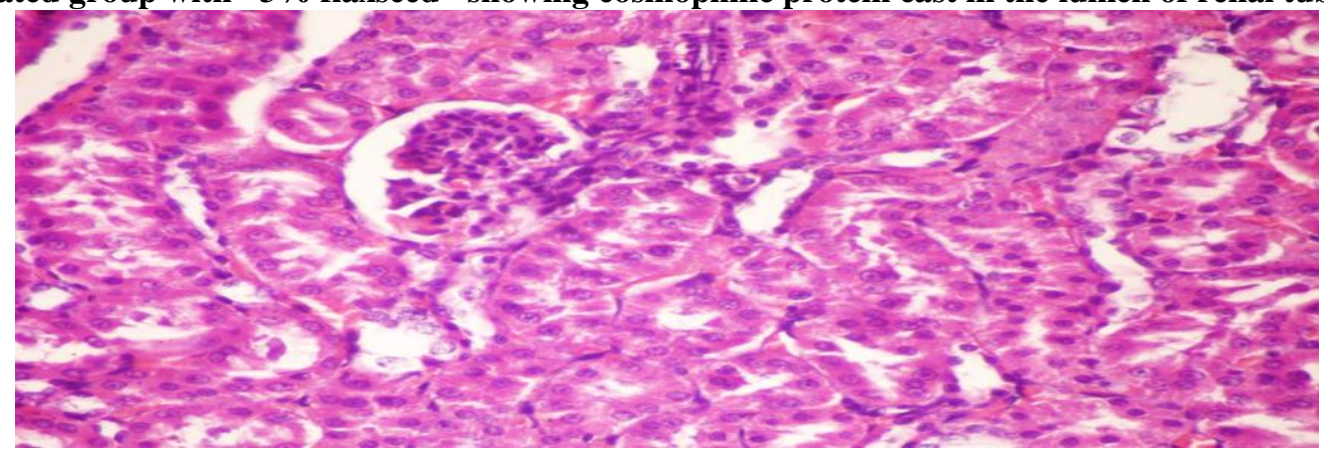

Treated group with "3\% flaxseed" showing no histotopathological changes. (H and E, x400).

Treatment 5\% FS

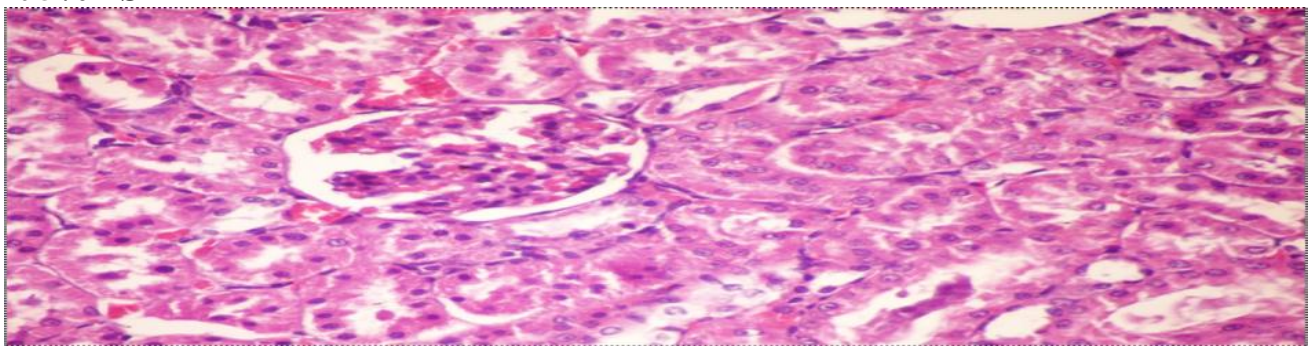

Treated group with "5\% flaxseed" showing congestion of glomerular tuft (H and E, x400).

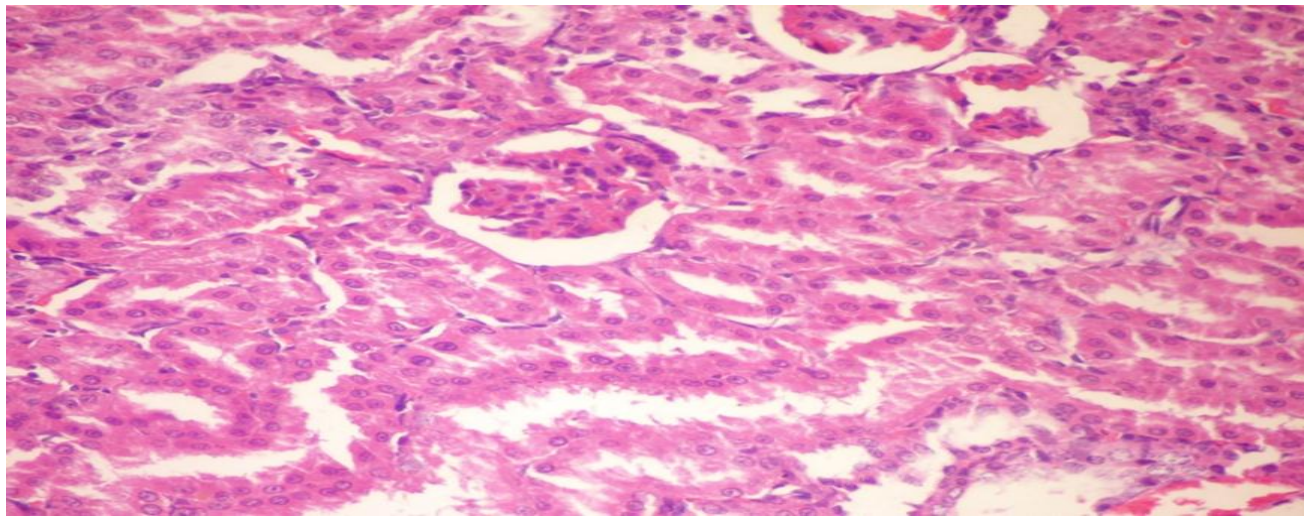

Treated group with "5\% flaxseed" showing no histopathological changes (H and E, x400). Treated group with "7\% flaxseed"

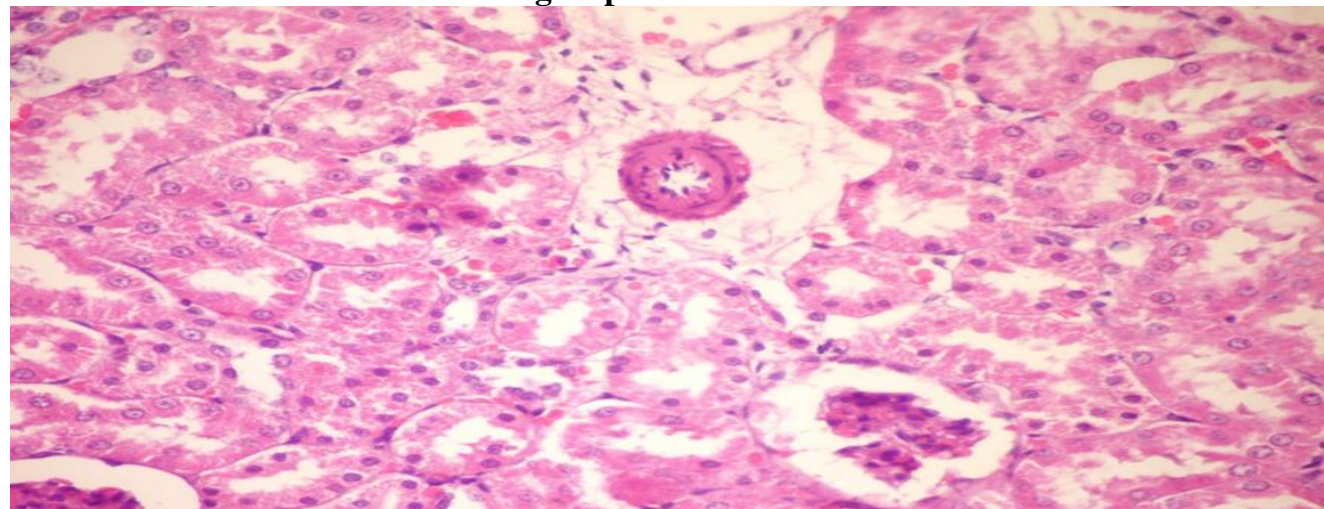

Treated group with "7\% flaxseed" showing Perivascular oedema (H and E, x400). 